\title{
The Genome Reduction Excludes the Ribosomal Rescue System in Acholeplasmataceae
}

\author{
Christina Zübert ${ }^{a} \quad$ Anna-Marie Ilic $^{a} \quad$ Bojan Duduk $^{b} \quad$ Michael Kube $^{a}$

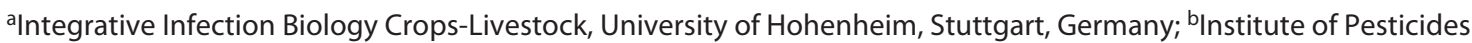 \\ and Environmental Protection, Belgrade, Serbia
}

\section{Keywords}

tmRNA · SmpB · ssrA - Trans-translation system · Ribosome rescue

\begin{abstract}
The trans-translation process is a ribosomal rescue system for stalled ribosomes processing truncated mRNA. The genes $s s r A$ and $s m p B$ fulfil the key functions in most bacteria, but some species have either lost these genes or the function of the ribosomal rescue system is taken over by other genes. To date, the ribosomal rescue system has not been analysed in detail for the Acholeplasmataceae. This family, in the Mollicutes class, comprises the genus Acholeplasma and the provisional taxon "Candidatus Phytoplasma". Despite their monophyletic origin, the two clades can be separated by traits such as not representing primary pathogens for acholeplasmas versus being phytopathogenic for the majority of phytoplasmas. Both taxa share reduced genomes, but only phytoplasma genomes are characterised by a remarkable level of instability and reduction. Despite the general relevance of the ribosomal rescue system, information is lacking on coding, the genomic context and pseudogenisation of $s m p B$ and ssrA and their possible application as a phyloge-
\end{abstract}

karger@karger.com www.karger.com/mip

Karger $\stackrel{\text { ' }}{5}$
(C) 2022 The Author(s)

Published by S. Karger AG, Basel

This is an Open Access article licensed under the Creative Common Attribution-NonCommercial-4.0 International License (CC BY-NC) (http://www.karger.com/Services/OpenAccessLicense), applicable to the online version of the article only. Usage and distribution for commercial purposes requires written permission. netic marker. Herein, we provide a comprehensive analysis of the ribosomal rescue system in members of Acholeplasmataceae. The examined Acholeplasmataceae genomes encode a ribosomal rescue system, which depends on tmRNA encoded by ssrA acting in combination with its binding protein SmpB. Conserved gene synteny is evident for $s m p B$, while ssrA shows a less conserved genomic context. Analysis of the tmRNA sequences highlights the variability of proteolysis tag sequences and short conserved sites at the $5^{\prime}$ - and $3^{\prime}$-ends. Analyses of $s m p B$ provided no hints regarding the coding of pseudogenes, but they did suggest its application as a phylogenetic marker of Acholeplasmataceae - in accordance with $16 \mathrm{~S}$ rDNA topology. Sequence variability of $\mathrm{smp} B$ provides sufficient information for species assignment and phylogenetic analysis.

(C) 2022 The Author(s).

Published by S. Karger AG, Basel

\section{Introduction}

The ribosomal rescue system in bacteria enables the release of ribosomes that have stalled due to processed truncated mRNA. Such mRNAs are a result of the premature termination of gene transcription and/or endo- or 
exonucleolytic cleavage events. The rescue system has been reviewed in terms of its importance [Keiler, 2008; Janssen and Hayes, 2012; Himeno et al., 2014; Fritze et al., 2020]. It comprises a tmRNA and an $\mathrm{SmpB}$ protein. The small tmRNA is encoded by the ssrA gene ( 360 nt), which was formerly referred to as "10Sa-RNA" [Karzai et al., 1999], and has been described in a large number of bacteria after the first description in Escherichia coli [Ray and Apirion, 1979]. It is separated from structural RNAs by harbouring the tRNA and mRNA features elucidating the two encoded major functions - also reflected in the name "tmRNA" [Madigan et al., 2020]. An alaninetRNA-like part, carrying an acceptor stem and a T-arm, enables the alanine load via the corresponding tRNA synthetase and by entering the A-site of the held ribosome, while the mRNA region of the tmRNA is located at the P-site [Komine et al., 1994]. As a result, the tmRNA-mediated trans-translation of the unblocked ribosome commences. The produced polypeptide is tagged by the tmRNA-encoded terminal peptide part AANDENYALAA (acting as a proteolysis tag peptide), recognised as the template for C-terminal-acting proteases in E. coli [Tu et al., 1995; Withey and Friedman, 1999], which degrade the incomplete peptide chains [Keiler et al., 1996]. This process requires an essential accessory protein alongside the tmRNA, named "SmpB" for small protein B (e.g., 160 aa E. coli K12) [Karzai et al., 1999; Shimizu and Ueda, 2002]. SmpB increases the alanylation activity of tmRNA, but it is also indispensable in the addition of tag-peptides by enabling the ribosomal A-site binding of tmRNA [Karzai et al., 1999; Barends et al., 2001; Shimizu and Ueda, 2002]. Furthermore, it protects tmRNA from degradation by RNase $\mathrm{R}$ [Hong et al., 2005]. In order to fulfil its role, $\mathrm{SmpB}$ has a $\mathrm{C}$-terminal tail and a $\beta$-barrel domain at its core, with an oligonucleotide-binding (OB) fold [Dong et al., 2002; Someya et al., 2003]. SmpB and tmRNA in combination are essential for the trans-translation system and are encoded by most bacteria [Ge and Karzai, 2009]. However, an understanding emerges that in some bacteria, either a functional $s s r A$ cannot be found or $\operatorname{smp} B$ has an apparently inactivating mutation [Hudson et al., 2014]. These examples comprise "Candidatus Carsonella rudii” strain PC, a highly obligate endosymbiont of the psyllid Ctenarytaina eucalypti. It encodes rudiments of a tmRNA, and a SmpB lacking the central loop and the C-terminal $\alpha$-helix, thereby indicating pseudogenisation [Hudson et al., 2014]. This loss highlights the extreme genome reduction process of "Candidatus Carsonella rudii”, resulting in a genome size of $160 \mathrm{~kb}$ for strain Pv [Nakabachi et al., 2006]. There are also bacteria with frameshifted $\operatorname{smp} B$, such as Corynebacterium pseudotuberculosis 31, Mycobacterium intracellulare MOTT2, Clostridium difficile str. CF5 and the str. M120, Buchnera aphidicola strains BCc and TLW03, Pectobacterium carotovorum PCC21, Aggregatibacter actinomycetemcomitans ANH9381, Pseudomonas putida DOT-T1E, Simiduia agarivorans SA1, Mycoplasma pneumoniae $\mathrm{FH}$, Thermotoga maritima MSB8, Petrotoga mobilis SJ95 and bacteria with truncated (the Tremblaya princeps strains PCIT and PCVAL) or pseudogenised $\operatorname{smpB}$ (Hodgkinia cicadicola TETUND1). This process is seen as part of an evolutionary adaptation, and it has been observed in particular for bacteria enabled for intracellular colonisation, often characterised by genome reduction [Merhej et al., 2009]. Bacteria in the Mollicutes class are characterised by this type of degenerative evolution from gram-positive ancestors [Woese et al., 1980]. However, SmpB has been suggested as being part of the core gene set of minimal genomes [Mushegian and Koonin, 1996; Gil et al., 2004; Glass et al., 2006], and it has been shown to be preserved in species such as Mycoplasma genitalium [Fraser et al., 1995], which was used, due to its simplicity and small gene set, as a model for constructing the first synthetic cell. Despite the identification of the $\operatorname{smp} B$ gene in all Mollicutes [Grosjean et al., 2014], the highly adapted haemotrophic mycoplasmas lost the central loop region of SmpB [Hudson et al., 2014]. In addition, tmRNA seems to be absent from the Mycoplasma suis-subclade [Hudson et al., 2014]. The latter has been shown for Mycoplasma haemolamae Purdue, Mycoplasma suis Illinois, Mycoplasma wenyonii Massachusetts and Mycoplasma suis KI3806. No alternative ribosome rescue system, such as ArfA/ ArfB, seems to be encoded in the small genomes of these highly adapted Mollicutes [Grosjean et al., 2014].

In contrast to other major branches of Mollicutes, Acholeplasmataceae have not yet been examined in this respect in detail. This monophyletic branch consists of the eponymous genus Acholeplasma and the provisional taxon "Candidatus Phytoplasma" [IRPCM, 2004]. Phytoplasmas are known as insect-transmitted bacteria associated with hundreds of plant diseases, including those affecting many important crops [reviewed by Bertaccini and Duduk, 2009; Maejima et al., 2014; Kumari et al., 2019]. Acholeplasmas can be found as saprophytes in a variety of habitats or as commensals of vertebrates, insects, or plants. Differences between phytoplasmas and acholeplasmas are obvious on the genome level. Complete phytoplasma genomes range from $576 \mathrm{~kb}$ ("Candidatus Phytoplasma asteris" M3, acc. no. CP015149.1) to $960 \mathrm{~kb}$ ("Candidatus Phytoplasma australiense" NZSb11,
Zübert/Ilic/Duduk/Kube 
acc. no. CP002548.1), while acholeplasmas range from $1,456 \mathrm{~kb}$ (Acholeplasma hippikon, acc. no. LR215050.1) to $1,883 \mathrm{~kb}$ (Acholeplasma axanthum, acc. no. LR215048.1) in complete size. Acholeplasmas and phytoplasmas lack the genes involved in major metabolic pathways in bacteria, such as the tricarboxylic acid cycle [Manolukas et al., 1988], oxidative phosphorylation [Razin, 1978; Miles, 1992], the de novo synthesis of purine and pyrimidine bases [Oshima et al., 2004; Bizarro and Schuck, 2007] and major aspects of amino acid biosynthesis [Kube et al., 2014]. As noted in other fermenting Mollicutes, like $M y$ coplasma genitalium [Fraser et al., 1995], glycolysis is the main pathway for generating ATP in acholeplasmas [Lazarev et al., 2011; Kube et al., 2014]. However, in phytoplasma genomes, a glucose-phosphorylating hexokinase and a sugar-specific phosphotransferase system (PTS) seem to be missing [Kube et al., 2012]; furthermore, an incomplete genetic repertoire for glycolysis has been identified in "Candidatus Phytoplasma mali" AT [Kube et al., 2008]. Compared to acholeplasmas, phytoplasma genomes lose additional important metabolic capabilities such as the pentose phosphate cycle [Kube et al., 2014] and a complete $\mathrm{F}_{\mathrm{O}} \mathrm{F}_{1}$ ATP synthase [Oshima et al., 2004; Kube et al., 2014], as well as the biosynthesis of fatty acids, isoprenoids, carotenoids and sterol [Kube et al., 2014]. Beside genome reduction, phytoplasmas are also characterised by genome instability caused by phage integration events, as well as transposons forming so-called "potential mobile units" [Bai et al., 2006; Kube et al., 2008; TranNguyen et al., 2008; Wei et al., 2008; Toruño et al., 2010; Andersen et al., 2013; Wang et al., 2018]. These circumstances also limit the selection of genetic markers for diagnostics of phytoplasmas relying on molecular techniques such as PCR approaches and follow-up sequence analysis, e.g., on $16 \mathrm{~S} \mathrm{rDNA}$, as well as on ribosomal proteins, chaperons, elongation factors, etc. [Seemüller et al., 1994; Schneider et al., 1997; Lee et al., 1998; Duduk and Bertaccini, 2011; Mitrović et al., 2011]. Phylogenetic and epidemiological studies on these bacteria increase the demands of applicable candidate genes shared by members of the Acholeplasmataceae but also carrying variable/informative sequences. The ribosomal rescue system may provide such genetic markers, but genome reduction raises the question as to whether the ribosomal rescue system is affected and, if so, to what degree. Herein, the ribosomal rescue system of Acholeplasmataceae was examined in detail with respect to key gene coding, conserved synteny, functionality and a possible application as a phylogenetic marker.

Ribosomal Rescue in Acholeplasmataceae

\section{Results}

Complete genomes from the Acholeplasmataceae encode the key genes $s s r A$ and $s m p B$ of the ribosomal rescue system. These single-copy genes show no frameshifts, truncations or other indications of function loss. The size of $s s r A$ varies from $338 \mathrm{nt}$ to $507 \mathrm{nt}$, whilst the encoded peptide tag ranges from 11 aa to 37 aa. The length of $\operatorname{sip} p B$ ranges from $441 \mathrm{nt}$ to $528 \mathrm{nt}$. No additional proteins forming an alternative ribosomal rescue system, such as ArfA/ArfB described for E. coli [Chadani et al., 2010; Chadani et al., 2011], were identified.

\section{The Genetic Context of Ribosomal Rescue System Genes}

The genes smpB and ssr $A$ are not located in close proximity on the chromosomes. A conserved genomic context is given for ssr A in "Candidatus Phytoplasma australiense" and "Candidatus Phytoplasma asteris" (online suppl. Fig. S1a, b; see www.karger.com/doi/10.1159/000520450 for all online suppl. material) but not in acholeplasmas (online suppl. Fig. S1c). In 4 of the 7 acholeplasmas, ssrA is flanked downstream by an IS3 family transposase, indicating the possible instability of this region. A less heterogenic situation is present for $s m p B$ genes flanked in phytoplasmas by an inorganic pyrophosphatase encoding gene $(p p a)$ and in most acholeplasmas by ribonuclease $\mathrm{R}$ (RNase R) encoding gene as shown in Figure 1, thus highlighting a conserved genus-specific context on one border. The $3^{\prime}-5^{\prime}$ exoribonuclease RNAse $\mathrm{R}$ is involved in degrading non-stop and defective mRNAs - and thereby providing a functional partner with the SmpB-tmRNA system in the trans-translation process [Richards et al., 2006]. The analyses highlight the increasing loss of the conserved gene order corresponding to the decreasing relatedness of taxa, albeit without an impact on the gene integrity of $s m p B$ and $s s r A$.

\section{tmRNA and Encoded Peptide Proteolysis Tag}

The deduced tmRNA sequences analysed herein have a conserved 5' - (GGGG) and $3^{\prime}$-end (CCACCA), in accordance with E. coli [Komine et al., 1994; Ushida et al., 1994; Karzai et al., 2000]. Based on amino acid sequence similarity, mainly for the conserved C-terminus, it was possible to identify the proteolytic tag peptide sequence of the tmRNA coding region (online suppl. Fig. S2). The tmRNA of Acholeplasmataceae members has a conserved region, starting with AUA as shown in Figure 2. In all analysed tmRNA sequences, this triplet is part of an open reading frame. In the genome of 3 strains, i.e., Achole- 
Fig. 1. Gene order of the conserved anchoring of $\operatorname{smp} B$. Regions encode inorganic pyrophosphatase and hypothetical proteins in the phytoplasmas region $(\mathrm{Pa}, \mathrm{Pb})$, except for E. purpurea witches' broom phytoplasma $(\mathrm{Pc})$, which is bordered by a gene encoding Hsp20/alpha crystallin family protein instead of a hypothetical protein, and by ribonuclease $\mathrm{R}(r n r)$ and patatin-like phospholipase family proteins in acholeplasmas (Aa), except for A. palmae (Ab), which is anchored by a phosphatase instead of patatin. Arrows symbolise forward or reverse strand coding, and information on the deduced gene products is provided. * Non-homologous conserved hypothetical proteins in the "Ca. P. asteris" and australiense group. ** Non-homologous hypothetical proteins.
(Pa)

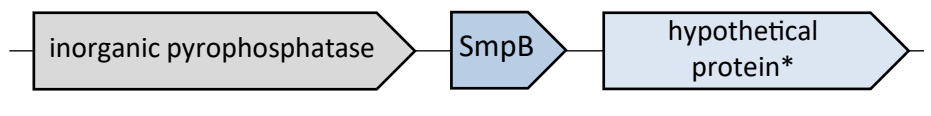

'Ca. P. asteris', 'Ca. P. australiense'

$(\mathrm{Pb})$

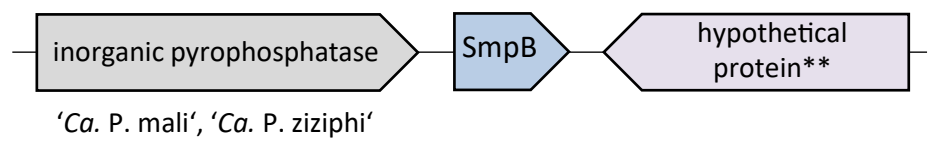

(Pc)

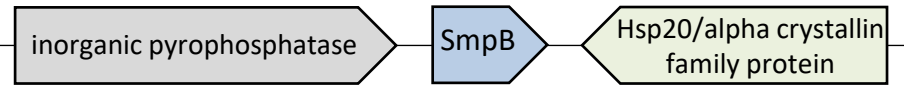

Echinacea purpurea witches' broom phytoplasma

(Aa)

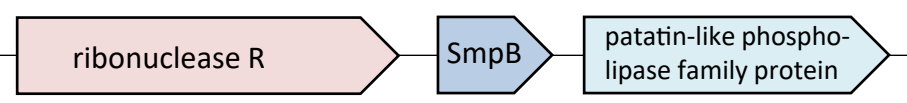

A. oculi, A. axanthum, A. brassicae, A. hippikon, A. laidlawii NCTC10116 and $A$. laidlawii PG-8

(Ab)

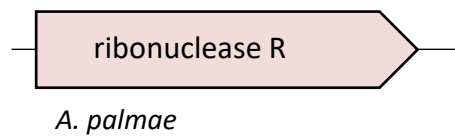

phosphatase PAP2 family protein plasma brassicae, Italian clover phyllody phytoplasma and "Ca. P. mali", a stop codon is located close upstream. The terminator TAA marks the $3^{\prime}$-end of the coding region in genomes of the Acholeplasmataceae.

Within phytoplasmas, all "Ca. P. asteris"-related strains share the same conserved $\mathrm{N}$-terminal nucleotide sequence (5'-ATA ACC GGA AAT-3') in the encoded peptide proteolysis tag, which translates into the amino acid sequence ITGN. "Ca. P. australiense" $(r p-\mathrm{A})$ and "Ca. P. australiense" NZSb11 share 5'-ATA ACT GGA AAA-3', while " $\mathrm{Ca}$. P. solani" has an ACC triplet in the second position (5'-ATA ACC GGA AAA-3'), like " $\mathrm{Ca}$. $P$. asteris"-related strains available, although both variants result in an amino acid motif ITGK. Echinacea purpurea witches' broom phytoplasma NCHU2014, Italian clover phyllody (both 5'-ATA AAC GGC AAT-3') and “Ca. P. ziziphi” (5'-ATA AAT GGC AAT-3') share an amino acid sequence (INGN), whereas " $\mathrm{Ca}$. P. mali" exhibits a different conserved sequence (5'-ATA AAC GAC GAA-3', INDE). For all phytoplasma sequences, except for " $\mathrm{Ca}$. P. mali", there is a conserved $\mathrm{N}$-terminal amino acid sequence of $\mathrm{I} \phi \mathrm{G} \Phi(\phi=\mathrm{T} / \mathrm{N} ; \phi=\mathrm{N} / \mathrm{K})$.

A similarly heterogeneous situation prevails for the peptide ending. "Ca. P. asteris", "Ca. P. australiense" and "Ca. P. solani" share a conserved peptide ending of LAFA, except for “Ca. P. tritici” (LVFA). "Ca. P. mali” (AFLS),
E. purpurea witches' broom phytoplasma (HATA) and Italian clover phyllody phytoplasma (TASC) show no conserved C-terminal regions (online suppl. Fig. S3).

Within Acholeplasma species, the start of the peptide coding sequence is highly conserved (5'-ATA ACC GGA AAC-3'). In Acholeplasma palmae (5'-ATA ACC GGA AAT-3') and Acholeplasma equifetale (5'-ATA TCC GGA AAC-3'), there is one base deviation. All acholeplasmas share a conserved amino acid motif at the N-terminus (ITGN), except for A. equifetale (ISGN). A. palmae, A. brassicae, $A$. axanthum and $A$. modium exhibit a C-terminal sequence of $\Phi$ AA $(\Phi=F / L)$, whereas the other Acholeplasma species share the consensus $\Phi \mathrm{A} \Phi \mathrm{A}(\Phi=$ L/Y/F) (online suppl. Fig. S4).

For all Acholeplasmataceae member sequences, except for "Ca. P. mali", there is a conserved N-terminal amino acid sequence of I $\Phi \mathrm{G} \Phi(\Phi=\mathrm{T} / \mathrm{N} / \mathrm{S} ; \Phi=\mathrm{N} / \mathrm{K})$. All of the $\mathrm{C}$-terminal residues are rather uncharged and hydrophobic (L, A, F, V, Y), and they are preceded by a cluster of polar and hydrophilic amino acids (T, Q, N, S), which are found in other eubacterial $s s r A$ encoded peptide sequences [Karzai et al., 2000].

\section{Application of smpB as a Phylogenetic Marker}

The $\operatorname{smp} B$ nucleotide sequences exhibited pairwise distances up to $49.4 \%$ (A. equifetale and "Ca. P. pruni”)
48

Microb Physiol 2022;32:45-56 DOI: $10.1159 / 000520450$
Zübert/Ilic/Duduk/Kube 


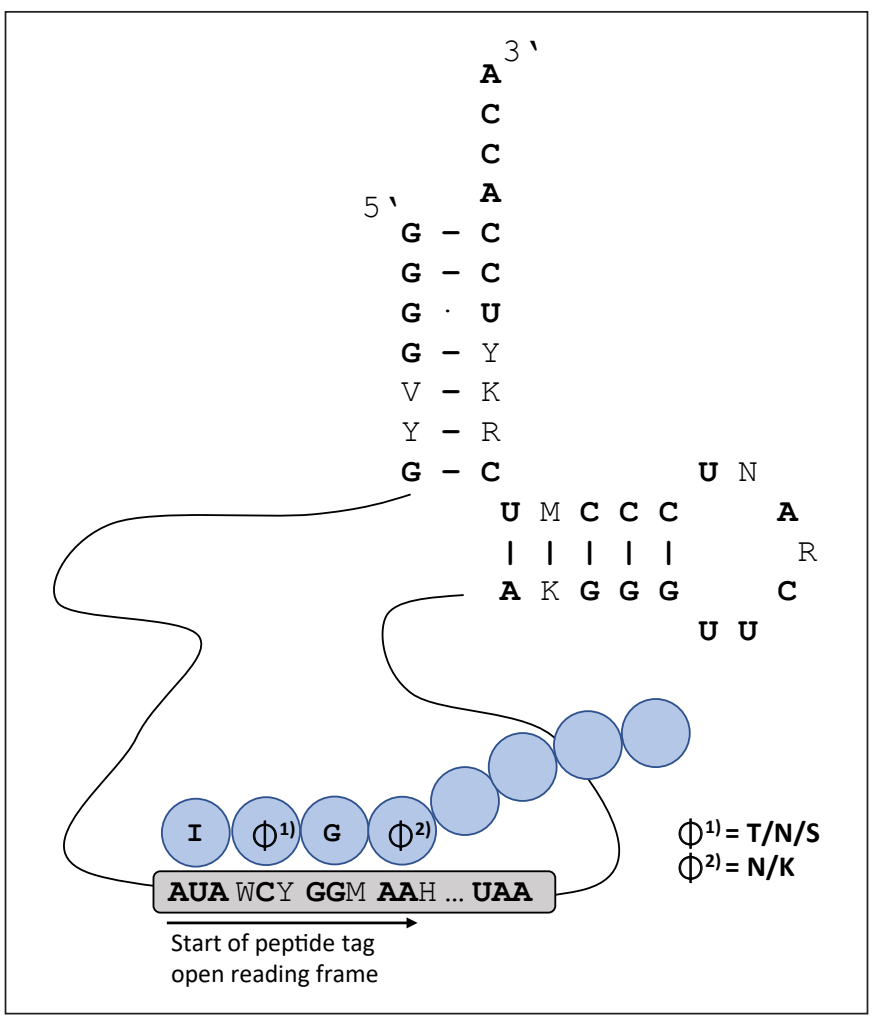

Fig. 2. Structure of Acholeplasmataceae tmRNA, highlighting its tRNA and mRNA properties. The first triplets of the peptide tag open-reading frame and deduced amino acids are indicated. There is a conserved N-terminal amino acid sequence of I $\Phi$ G $\Phi(\Phi=$ $\mathrm{T} / \mathrm{N} / \mathrm{S} ; \Phi=\mathrm{N} / \mathrm{K}$ ) for Acholeplasmataceae. "Ca. P. mali" has been excluded, due to large deviations. Seven nucleotides from the 5'end and 28 nucleotides from the $3^{\prime}$-end of tmRNA form a structure equivalent to an acceptor stem and a TFC stem-loop of tRNA, in accordance with $E$. coli secondary structure prediction [Komine et al., 1994]. Bases conserved within the Acholeplasmataceae are indicated in bold, and differences are indicated with wobbles coding.

(online suppl. Fig. S5). The distances within Acholeplasma species ranged from $21.1 \%$ (Acholeplasma laidlawii and Acholeplasma granularum) to $44.8 \%$ (A. equifetale and A. brassicae). Distances between "Candidatus Phytoplasma" clusters ranged from 19.2\% ( "Ca. P. australiense" NZSb11 and "Ca. P. asteris" OY-V, M3 and DY2014) to $34.7 \%$ ("Ca. P. pruni" CX and "Ca. P. australiense" (rpA)), whereas the distances within clusters dropped, while some also exhibited identical sequences.

The high number of deviations in the tmRNA sequences in members of the Acholeplasmataceae disqualified them for application in phylogenetic analyses (data not shown), in contrast to $\operatorname{smp} B$, which enables the evolutionary reconstruction of species and in some cases strain differentiation (shown in Fig. 3). Furthermore, the phylogenetic reconstruction also agreed with $16 \mathrm{~S}$ rDNA analysis (online suppl. Fig. S6).

\section{Discussion}

It has been established herein that the ribosomal rescue system is a core genetic feature among members of the Acholeplasmataceae despite the fact that the genomic context of the key genes $s s r A$ and $s m p B$ is not well conserved. Hudson et al. [2014] described $s s r A$ as one of the most frequent neighbours of $\operatorname{smp} B$, together with rat $A$ (RatA toxin-inhibiting 70S ribosome association), $r n f H$ (RnfH of ubiquitin superfamily) and RNase R. None of those genes identified is in direct proximity with the $\operatorname{smp} B$ of Acholeplasmataceae members analysed in this study, except for RNase R.

Despite the softened gene order within the genera, no hints for the pseudogenisation of the key genes have been obtained. Both tmRNA and SmpB retain general motifs beside group-specific features, and the 3 '-terminal CAA trinucleotide is described as typical for mature tRNAs and tmRNAs [Komine et al., 1994; Ushida et al., 1994; Karzai et al., 2000]. In E. coli, pre-tmRNA must be processed into a mature and functional tmRNA. Therefore, cleavage at the $5^{\prime}$-end by RNAse P [Komine et al., 1994], and $3^{\prime}$-end trimming by exoribonucleases, is necessary [Li et al., 1998] in a process which resembles that of canonical tRNA. These conserved endings are important for $5^{\prime}$ - and $3^{\prime}$-pairing in secondary structure formation [Zwieb et al., 1999]. Alignments indicate (online suppl. Fig. S2) that the $3^{\prime}$ - and $5^{\prime}$-endings of tmRNA sequences are conserved, in contrast to the middle parts. The conserved amino acid start motif for tmRNA-mediated peptide tagging and proteolysis in members of the Acholeplasmataceae does not match the one identified in E. coli [Keiler et al., 1996] and other Mollicutes, such as M. pneumoniae (DKNNDEVLVDPMLIANQQASINYAFA) [Zwieb et al., 1999] and M. genitalium (DKENNEVLVDPNLIINQQASVNFAFA) [Karzai et al., 2000]. This may indicate that Acholeplasmataceae members exhibit a distinct amino acid start motif. The situation differs for mycoplasma ssrA tag endings, which are important for recognition by proteases, showing the consensus sequence $\mathrm{N} \Phi \mathrm{A} \Phi \mathrm{A}(\Phi=\mathrm{F} / \mathrm{Y} / \mathrm{L})$ [Gur and Sauer, 2008]. For Acholeplasmataceae members, this motif can be found in A. hippikon (NYALA), but it is less conserved ( $\Phi \mathrm{A} \Phi \mathrm{A}$ $(\Phi=\mathrm{F} / \mathrm{Y} / \mathrm{L})$ ) in other Acholeplasma species (A. equifetale, A. oculi, A. granularum, A. laidlawii) and in "Ca. P. aus- 


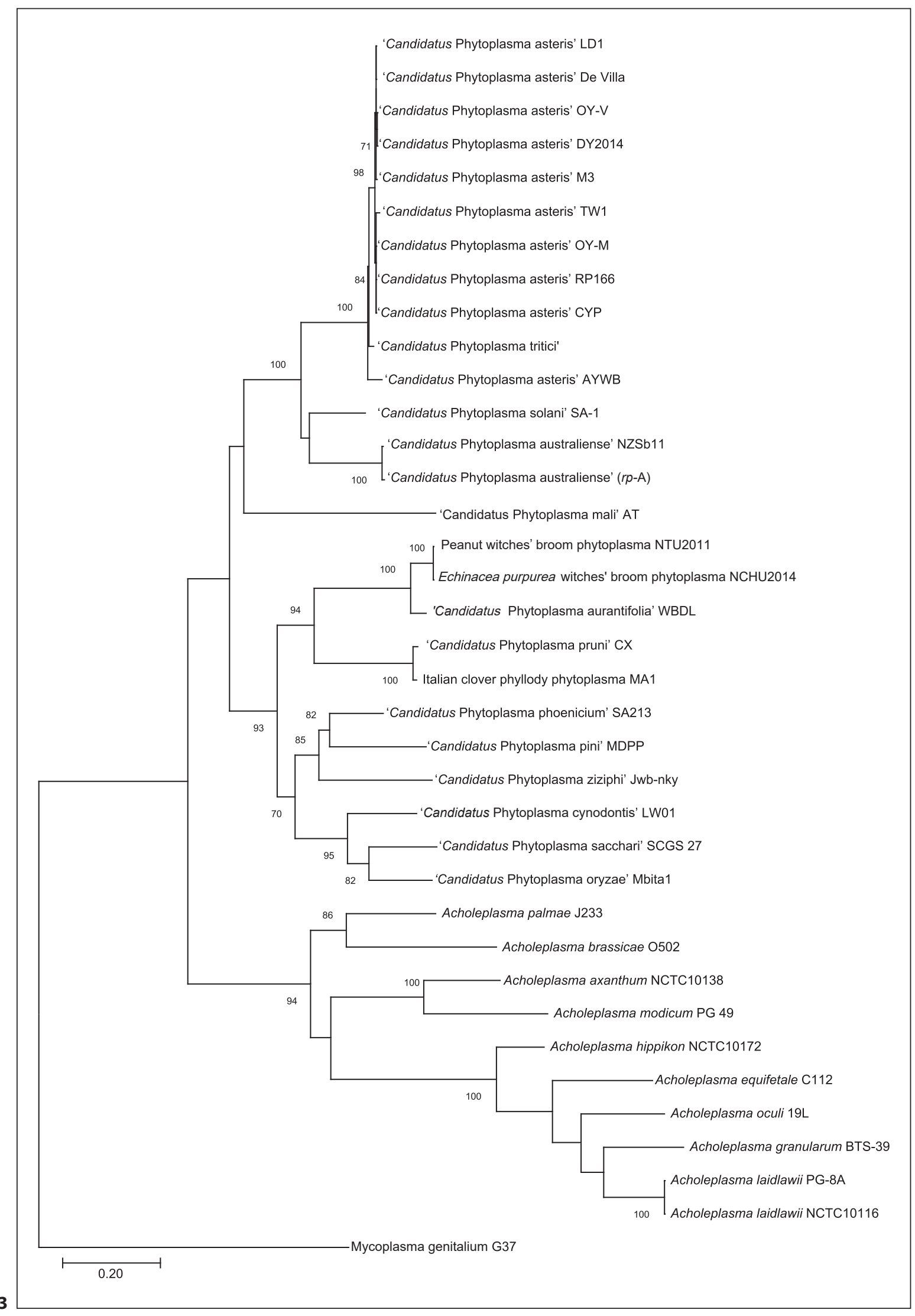


traliense" and "Ca. P. asteris" (except "Ca. P. tritici" LVFA). "Ca. P. mali" differs in its putative start and ending for the $s s r A$-encoded proteolytic tag, but it has enough conserved motifs to be identified as the protein coding sequence for proteolytic tag peptide (HG521554.1) [de Novoa and Williams, 2004]. E. purpurea witches' broom phytoplasma and Italian clover phyllody phytoplasma share the same conserved start but differ in their proteolytic tag peptide ending region.

It was demonstrated for Mycoplasma pneumoniae [Ge and Karzai, 2009], a reduced-genome intracellular bacterial pathogen, and Mesoplasma florum [Gur and Sauer, 2008], one of the smallest free-living epiphytic bacteria, that the $s s r A$-tag is adapted to an AAA+ Lon protease instead of ClpXP and that the C-terminal region contains the highest information for protease recognition. In these bacteria, tmRNA and Lon protease co-evolved, and ClpXP protease was lost, indicating the importance of this proteolytic quality control system. Furthermore, it was shown for these two species that the two aromatic amino acids, besides the two alanine residues, in their peptidase peptide tag $3^{\prime}$-ending (YAFA) offer effective proteolysis via Lon protease. Substituting both aromatic amino acids resulted in the poor degradation of tagged proteins by $M$. florum Lon protease [Gur and Sauer, 2008]. In most members of the Acholeplasmataceae, tyrosine ( $\mathrm{Y}$ ) is replaced by a nonaromatic amino acid (leucin, L), leading to LAFA (A. granularum, A. laidlawii, "Ca. P. ziziphi”, "Ca. P. australiense" and "Ca. P. asteris", except for "Ca. P. tritici"). It is likely that the penultimate phenylalanine $(F)$ in place of alanine (A), compared to E. coli, in tagged proteins is optimised for degradation by AAA+ proteases FtsH [Karzai et al., 2000] or Lon [Gur and Sauer, 2008], instead of ClpX, which is lost in mycoplasmas. To our knowledge, there is also no documentation for the presence of $c l p X$ gene in Acholeplasmatacae members, which is supported by database searches. In some Acholeplasma species, one aromatic amino acid is missing, leading to FAA (A. palmae, A. brassicae and A. modium) or LAA (A. axanthum). In this case, it is hypothesized that the degradation by Lon protease still takes place. As Lon protease is cytoplasmatic,

Fig. 3. Phylogenetic analysis of $\operatorname{smp} B$ in Acholeplasmataceae. The tree is inferred from $\operatorname{smp} B$ nucleotide sequences, using the Maximum Likelihood method and the Tamura-Nei model [Tamura and Nei, 1993]. In total, there are 574 positions in the final dataset. The bootstrapped confidence interval is based on 1,000 replications, and bootstrap values over $70 \%$ are shown on the branches. Evolutionary analyses were conducted in MEGA X [Kumar et al., 2018]. M. genitalium is used as an outgroup.

Ribosomal Rescue in Acholeplasmataceae it is likely to play a major role in the degradation of tagged peptides [Gur and Sauer, 2008; Ge and Karzai, 2009]. Genomes of Acholeplasmataceae members in this study encode for a Lon protease. They all belong to the Lon protease family, are bacterial/eukaryotic-type (IPR004815) and have an ATP-dependent protease La (LON) substratebinding domain, an AAA + ATPase domain and a Lon protease (S16) C-terminal proteolytic domain. It is already known that proteolysis tag peptides in most mycoplasma species are longer than those observed in other bacterial groups [Ge and Karzai, 2009] - a fact that could be also observed for members of the Acholeplasmataceae. The extended proteolytic tag was revealed to provide a better recognition signal for Lon protease in $M$. pneumoniae, but it could also contain signals for recognition by FtsH proteases [Ge and Karzai, 2009]. The HAMAP family profile for FtsH protease (MF_01458) enabled identification in all UniProtKB reference proteomes of Acholeplasmatacae members. This finding is supported by Blast searches of the examined complete genomes in this study. Interestingly, FtsH in "flavescence dorée" phytoplasma is suspected to have an extracellular function for host protein degradation, either for nutrition purposes or as a defense mechanism [Jollard et al., 2020]. "Ca. P. mali" has several copies of $f t s H$, and it is possible to separate mild from severe virulent strains using $f t s H$ sequences [Seemüller et al., 2013].

In addition to the functional reconstruction, the $\operatorname{smp} B$ sequences enabled phylogenetic analysis in contrast to ssr $A$. This might be due to sequence differences in the middle part of $s s r A$ in phytoplasmas and acholeplasmas, whereas the multiple alignment is well conserved at the 5 '- ( 95 bases) and 3 '-endings ( $~ 74$ bases). This outcome is in a line with gram-positive bacteria of low $\mathrm{G}+\mathrm{C}$ content, e.g., Lactococcus, Lactobacillus, Leuconostoc and Enterococcus, limiting phylogenetic application to the species or genus level [Schönhuber et al., 2001]. By contrast, in case of alphaproteobacterial tmRNA sequences the application performs well [Mao et al., 2009].

This study highlights that the ribosomal rescue system, with its key genes $s s r A$ and $\operatorname{smp} B$, belongs to the core functions of Acholeplasmataceae members. The ssrA gene differs in terms of its genetic context and its encoded proteolytic tag between phytoplasmas and acholeplasmas. A stable genetic context on the chromosome is observed in some "Candidatus Phytoplasma" species, but it is not apparent in the acholeplasmas. Apart from a shared start codon, proteolytic tags differ between phytoplasma species, while the majority of acholeplasmas encode a conserved $\mathrm{N}$-terminus of the amino acid tag. The $\mathrm{N}$-terminal 
Table 1. Accession numbers of genome sequences and $s m p B$ base range

\begin{tabular}{|c|c|c|}
\hline Taxon & Acc. No., base range & Length, nt \\
\hline Acholeplasma axanthum NCTC 10138 & LR215048.1, 1085411-1085857 & 447 \\
\hline Acholeplasma brassicae $\mathrm{O} 502$ & FO681348.1, c1130183-1129734 & 450 \\
\hline Acholeplasma hippikon NCTC10172 & LR215050.1, c627356-626886 & 471 \\
\hline Acholeplasma laidlawii PG-8A & CP000896.1, 427129-427578 & 450 \\
\hline Acholeplasma laidlawii NCTC10116 & LS483439.1, 425709-426158 & 450 \\
\hline Acholeplasma oculi 19L & LK028559.1, c1121419-1120949 & 471 \\
\hline Acholeplasma palmae $\mathrm{J} 233$ & FO681347.1, c1095332-1094889 & 444 \\
\hline Acholeplasma modicum PG 49 (ATCC 29102) & NZ_JHYB01000002.1, 152088-152531 & 444 \\
\hline Acholeplasma granularum BTS-39 (ATCC 19168) & NZ_JAFR01000006.1, 194990-195439 & 450 \\
\hline Acholeplasma equifetale C112 (ATCC 29724) & NZ_JHXL01000009.1, 11661-12110 & 450 \\
\hline "Candidatus Phytoplasma asteris" LD1 & MIEP01000004.1, 27059-27520 & 462 \\
\hline "Candidatus Phytoplasma asteris" De Villa & СР035949.1, с501449-500988 & 462 \\
\hline "Candidatus Phytoplasma asteris" OY-V & BBIY01000025.1, c10951-10493 & 459 \\
\hline "Candidatus Phytoplasma asteris" DY2014 & SRMC01000008.1, c176675-176217 & 459 \\
\hline "Candidatus Phytoplasma asteris" M3 & CP015149.1, c478812-478354 & 459 \\
\hline "Candidatus Phytoplasma asteris" TW1 & QGKT01000002.1, 320594-321085 & 492 \\
\hline "Candidatus Phytoplasma asteris" OY-M & AP006628.2, 172267-172725 & 459 \\
\hline "Candidatus Phytoplasma asteris" RP166 & CP055264.1, 263909-264367 & 459 \\
\hline "Candidatus Phytoplasma asteris" CYP & NZ_JSWH01000095.1, 3074-3532 & 459 \\
\hline "Candidatus Phytoplasma tritici" & NZ_AVAO01000001.1, 77784-78245 & 462 \\
\hline "Candidatus Phytoplasma asteris" AYWB & СР000061.1, с595870-595412 & 459 \\
\hline "Candidatus Phytoplasma solani" SA-1 & MPBG01000008.1, 27632-28084 & 453 \\
\hline "Candidatus Phytoplasma australiense" NZSb11 & CP002548.1, 339568-340098 & 531 \\
\hline "Candidatus Phytoplasma australiense" (rp-A) & AM422018.1, 596833-597363 & 531 \\
\hline "Candidatus Phytoplasma mali" AT & CU469464.1, c410449-409994 & 456 \\
\hline Peanut witches' broom phytoplasma NTU2011 & AMWZ01000008.1, c21340-20891 & 450 \\
\hline Echinacea purpurea witches' broom phytoplasma NCHU2014 & СР040925.1, c528047-527598 & 450 \\
\hline "Candidatus Phytoplasma aurantifolia" WBDL & MWKN01000047.1, c9977-9528 & 450 \\
\hline "Candidatus Phytoplasma pruni" CX & LHCF01000009.1, 3795-4247 & 453 \\
\hline Italian clover phyllody phytoplasma MA1 & NZ_AKIM01000028.1, c12328-11876 & 453 \\
\hline "Candidatus Phytoplasma phoenicium" SA213 & JPSQ01000073.1, 2133-2582 & 450 \\
\hline "Candidatus Phytoplasma pini" MDPP & VIAE01000002.1, c63130-62684 & 447 \\
\hline "Candidatus Phytoplasma ziziphi" Jwb-nky & СР025121.1, 431978-432424 & 447 \\
\hline "Candidatus Phytoplasma cynodontis" LW01 & VWOH01000004.1, 2204-2674 & 471 \\
\hline "Candidatus Phytoplasma sacchari" SCGS 27 & VWXM01000026.1, 2007-2465 & 459 \\
\hline "Candidatus Phytoplasma oryzae" Mbita 1 & LTBM01000013.1, c9696-9238 & 459 \\
\hline Mycoplasma genitalium G37 & L43967.2, c67643-67206 & 438 \\
\hline
\end{tabular}

ITGN motive is also shared with the "Ca. P. asteris" strains but differs from other "Candidatus Phytoplasma" species. In contrast, $\operatorname{smp} B$ has a genus-specific genomic context and is applicable for the phylogenetic analysis of Acholeplasmataceae, thereby suggesting it as a marker gene in follow-up studies.

\section{Materials and Methods}

\section{Sequences}

SmpB protein sequences were retrieved from the Universal Protein Resource (uniprot.org) for Acholeplasmataceae with the taxonomy ID 2146 and a HAMAP family profile MF_00023. Ad- ditional sequences were identified by BLASTP, against NCBIs non-redundant protein database (www.ncbi.nlm.nih.gov). Thirtyseven SmpB sequences were selected (online suppl. Table S1), belonging to the Interpro SsrA-binding protein family (IPR000037) and the CDD conserved protein domain family SmpB (cd09294), containing information about residues and positions at the SmpBtmRNA interface. Based on protein IDs, nucleotide sequences were downloaded from the NCBIs nucleotide database (Table 1).

The tmRNA sequences were retrieved from RNAcentral version 15 [Petrov et al., 2017], manually inspected, compared and then supplemented by sequences identified by BLASTN and GenBank nucleotide and genome entries (Table 2). The proteolysis tag peptide was identified by sequence similarly in " $\mathrm{Ca}$. P. mali" (CDK05131.1), "Ca. P. asteris" OY-M (CDK05070.1), "Ca. P. asteris" AYWB (CDK05069.1), “Ca. P. australiense" NZSb11
52

Microb Physiol 2022;32:45-56

DOI: $10.1159 / 000520450$
Zübert/Ilic/Duduk/Kube 
Table 2. Accession numbers of genome sequences and tmRNA locus tag or base range

\begin{tabular}{|c|c|}
\hline Taxon & Acc. No., locus tag or base range \\
\hline Acholeplasma axanthum NCTC10138 & NZ_LR215048.1,EXC62_RS06055 \\
\hline Acholeplasma brassicae 0502 & NC_022549.1, BN853_RS08760 \\
\hline Acholeplasma hippikon NCTC10172 & NZ_LR215050.1,EXC59_RS02450 \\
\hline Acholeplasma laidlawii PG8 & NC_010163.1,ACL_RS07410 \\
\hline Acholeplasma laidlawii NCTC10116 & NZ_LS483439.1, DQ̄N27_RS03880 \\
\hline Acholeplasma oculi 19L & NZ_LK028559.1, VV22_RS07795 \\
\hline Acholeplasma palmae J233 & NC_022538.1,BN854_RS07560 \\
\hline Acholeplasma modicum PG 49 & NZ_JHYB01000002.1,T352_RS07010 \\
\hline Acholeplasma granularum BTS-39 & NZ_JAFR01000006.1, G324_RS07825 \\
\hline Acholeplasma equifetale $\mathrm{C} 112$ & NZ_JHXL01000001.1,T434_RS07615 \\
\hline "Candidatus Phytoplasma asteris" AYWB & NC_007716.1,AYWB_RS03535 \\
\hline “Candidatus Phytoplasma asteris" CYP & NZ_JSWH01000088.1, OL66_RS03690 \\
\hline "Candidatus Phytoplasma asteris" De Villa & NZ_CP035949.1, EXT02_RS00465 \\
\hline "Candidatus Phytoplasma asteris" LD1 & MIEP01000001.1, BHE82_00375 \\
\hline "Candidatus Phytoplasma asteris" M3 & NZ_CP015149.1, MBSPM3_RS00455 \\
\hline "Candidatus Phytoplasma asteris" NJAY & MAPF01000014.1, BBA70_00330 \\
\hline "Candidatus Phytoplasma asteris" OY-M & AP006628.2, 762465-762887 \\
\hline “Candidatus Phytoplasma asteris” OY-V & NZ_BBIY01000035.1, OYV_RS04620 \\
\hline “Candidatus Phytoplasma asteris” RP166 & CР055264.1, 740426-740850 \\
\hline "Candidatus Phytoplasma asteris" TW1 & QGKT01000002.1,DF280_02500 \\
\hline “Candidatus Phytoplasma australiense” (rp-A) & NC_010544.1,PAA_RS04365 \\
\hline "Candidatus Phytoplasma australiense" NZSb11 & NC_021236.1, SLY_RS05160 \\
\hline "Candidatus Phytoplasma mali" AT & NC_011047.1, c247166-247672 \\
\hline "Candidatus Phytoplasma solani" SA-1 & NZ_MPBG01000007.1,PSSA1_RS02600 \\
\hline "Candidatus Phytoplasma tritici" & NZ_AVAO01000002.1, N747_RS03775 \\
\hline "Candidatus Phytoplasma ziziphi" Jwb-nky & NZ_CP025121.1, 577912-578413 \\
\hline \multicolumn{2}{|l|}{ Phytoplasmas w/o detailed assignment in annotation } \\
\hline Echinacea purpurea witches' broom NCHU2014 & CP040925.1, 23588-23994 \\
\hline Italian clover phyllody phytoplasma str. MA1 & NZ_AKIM01000013.1, RI01_RS03350 \\
\hline
\end{tabular}

(CDK10644.1), “Ca. P. australiense” (rp-A) (CDK10643.1) and A. laidlawii PG-8A (CDK05533.1), using the Artemis genome browser [Carver et al., 2012]. The putative consensus start of a proteolysis tag peptide within the tmRNA sequence was defined by a conserved motif identified in nucleotide alignment, while the end was identified based on a conserved amino acid motif followed by a stop codon.

Encoded endopeptidase La (lon) was identified in genome entries (online suppl. Table S2). Protein families and domains were analysed with InterProScan [Jones et al., 2014].

Multiple sequence alignment of tmRNA and the proteolysis peptide tags was performed with CLUSTAL W (1.83), using TCOFFEE Version 11.00 [Notredame et al., 2000; Di Tommaso et al., 2011].

Phylogenetic Analyses

Nucleotide sequences of $\operatorname{smp} B$ gene were aligned by Clustal W, and a phylogenetic tree was reconstructed by using the Maximum Likelihood method and the Tamura-Nei model [Tamura and Nei, 1993] in MEGA X version 10.1.7 [Kumar et al., 2018]. A pairwise distance matrix was generated, using the p-distance method. All ambiguous positions were removed for each sequence pair (pairwise deletion option). In total, 573 positions were in the final dataset.

Ribosomal Rescue in Acholeplasmataceae
Table 3. Strains and GenBank entries used for examination of gene synteny (original submission and RefSeq annotation)

\begin{tabular}{ll}
\hline Taxon & GenBank \\
& (acc. No./RefSeq entry)
\end{tabular}

A. axanthum NCTC 10138

A. brassicae $\mathrm{O} 502$

A. hippikon NCTC10172

A. laidlawii PG-8A

A. laidlawii NCTC10116

A. oculi 19L

A. palmae $\mathrm{J} 233$

"Ca. P. asteris" AYWB

"Ca. P. asteris" De Villa

"Ca. P. asteris" M3

"Ca. P. asteris" OY-M

"Ca. P. asteris" RP166

"Ca. P. australiense" (rp-A)

"Ca. P. australiense" NZSb11

"Ca. P. mali" AT

"Ca. P. ziziphi" Jwb-nky

Echinacea purpurea witches'

broom phytoplasma NCHU2014 CP040925.1/-
LR215048.1/NZ LR215048.1 FO681348.1/NC_022549.1

LR215050.1/NZ_LR215050.1

CP000896.1/NC_010163.1

LS483439.1/NZ_LS483439.1

LK028559.1/NZ_LK028559.1

FO681347.1/NC_022538.1

CP000061.1/NC 007716.1

CP035949.1/NZ_CP035949.1

CP015149.1/NZ_CP015149.1

AP006628.2/-

CP055264.1/-

AM422018.1/NC_010544.1

CP002548.1/NC 021236.1

CU469464.1/-

CP025121.1/- 
The 16S rDNA sequences were retrieved manually from GenBank genome entries (online suppl. Table S1). "Ca. P. asteris" OY-V (BBIY00000000.1) lacks an annotated 16S rRNA gene entry. For "Ca. P. aurantifolia" and "Ca. P. oryzae", no $\operatorname{smpB}$ and $16 \mathrm{~S}$ rDNA sequences were available from the same strain. M. genitalium G37 (L43967.2) was used as the outgroup, and $s m p B$ and 16S rDNA sequences were accessed from NCBI's GenBank. Alignment was performed by Clustal W, and a phylogenetic tree was reconstructed by using the Maximum Likelihood method and the General Time Reversible model [Nei and Kumar, 2000] in MEGA X version 10.1.7 [Kumar et al., 2018]. The bootstrapped confidence interval was based on 1,000 replications.

All aligned matrices and trees were deposited in TreeBASE (www.treebase.org, accession number: 28778).

\section{Gene Synteny Analysis}

The gene context was analysed for $s s r A$ and $s m p B$ from complete genomes (Table 3 ) in the Artemis genome browser [Carver et al., 2012]. Base ranges are shown in online supplementary Table S3. The genetic context of $s m p B$ was identified in INSDC entries, while ssrA was detected in RefSeq entries. For genomes in which $s s r A$ was not annotated in the GenBank RefSeq genome entries, their position was inferred from their tmRNA nucleotide entries ("Ca. P. asteris" OY-M and "Ca. P. mali" AT) or BLASTN results (“Ca. P. ziziphi” Jwb-nky, “Ca. P. asteris” RP166 and E. purpurea witches' broom phytoplasma NCHU2014).

\section{Statement of Ethics}

Ethical approval was not required as this research did not require any human and or animal involvement.

\section{Conflict of Interest Statement}

The authors have no conflicts of interest to declare.

\section{Funding Sources}

There were no funding sources.

\section{Author Contributions}

C.Z. and A.-M.I. carried out data collection, analysis and interpretation. C.Z., B.D. and M.K. performed the phylogenetic analysis and drafted the article.

All authors read and approved the final manuscript. All authors agreed to be both personally accountable for their own contributions and to ensure that questions related to the accuracy or integrity of any part of the work, even ones in which the author was not personally involved, are appropriately investigated, resolved and the resolution documented in the literature.

\section{Data Availability Statement}

All data generated or analysed during this study are included in this article and its supplementary material files. The datasets for phylogenetic trees of Acholeplasmataceae (aligned matrices and trees) are deposited in TreeBASE (www.treebase.org/treebase, accession number: 28778).

\section{References}

Andersen MT, Liefting LW, Havukkala I, Beever RE. Comparison of the complete genome sequence of two closely related isolates of 'Candidatus Phytoplasma australiense' reveals genome plasticity. BMC Genomics. 2013;14: $529-15$.

Bai X, Zhang J, Ewing A, Miller SA, Radek AJ, Shevchenko DV, et al. Living with genome instability: The adaptation of phytoplasmas to diverse environments of their insect and plant hosts. J Bacteriol. 2006;188:3682-96.

Barends S, Karzai AW, Sauer RT, Wower J, Kraal B. Simultaneous and functional binding of SmpB and EF-Tu-TP to the alanyl acceptor arm of tmRNA. J Mol Biol. 2001;314:9-21.

Bertaccini A, Duduk B. Phytoplasma and phytoplasma diseases: A review of recent research. Phytopathol Mediterr. 2009;48:355-78.

Bizarro CV, Schuck DC. Purine and pyrimidine nucleotide metabolism in Mollicutes. Genet Mol Biol. 2007;30(1 Suppl 1):190-201.

Carver T, Harris SR, Berriman M, Parkhill J, McQuillan JA. Artemis: An integrated platform for visualization and analysis of highthroughput sequence-based experimental data. Bioinformatics. 2012;28:464-9.
Chadani Y, Ono K, Kutsukake K, Abo T. Escherichia coli YaeJ protein mediates a novel ribosome-rescue pathway distinct from SsrA- and ArfA-mediated pathways. Mol Microbiol. 2011;80:772-85.

Chadani Y, Ono K, Ozawa SI, Takahashi Y, Takai $\mathrm{K}$, Nanamiya $\mathrm{H}$, et al. Ribosome rescue by Escherichia coli ArfA (YhdL) in the absence of trans-translation system. Mol Microbiol. 2010;78:796-808.

de Novoa PG, Williams KP. The tmRNA website: Reductive evolution of tmRNA in plastids and other endosymbionts. Nucleic Acids Res. 2004;32:104-8.

Di Tommaso P, Moretti S, Xenarios I, Orobitg M, Montanyola A, Chang JM, et al. A web server for the multiple sequence alignment of protein and RNA sequences using structural information and homology extension. Nucleic Acids Res. 2011;39:13-7.

Dong G, Nowakowski J, Hoffman DW. Structure of small protein B: The protein component of the tmRNA-SmpB system for ribosome rescue. EMBO J. 2002;21:1845-54.

Duduk B, Bertaccini A. Phytoplasma classification: Taxonomy based on $16 \mathrm{~S}$ ribosomal gene, is it enough? Phyt Moll. 2011;1(1):313.

Fraser CM, Gocayne JD, White O, Adams MD, Clayton RA, Fleischmann RD, et al. The minimal gene complement of Mycoplasma genitalium. Science. 1995;270:397-403.

Fritze J, Zhang M, Luo Q, Lu X. An overview of the bacterial SsrA system modulating intracellular protein levels and activities. Appl Microbiol Biotechnol. 2020;104:5229-41.

Ge Z, Karzai AW. Co-evolution of multipartite interactions between an extended tmRNA tag and a robust Lon protease in Mycoplasma. Mol Microbiol. 2009;74:1083-99.

Gil R, Silva FJ, Peretó J, Moya A. Determination of the core of a minimal bacterial gene set. Microbiol Mol Biol Rev. 2004;68:518-37.

Glass JI, Assad-Garcia N, Alperovich N, Yooseph S, Lewis MR, Maruf M, et al. Essential genes of a minimal bacterium. Proc Natl Acad Sci U S A. 2006;103:425-30.

Grosjean H, Breton M, Sirand-Pugnet P, Tardy F, Thiaucourt F, Citti C, et al. Predicting the minimal translation apparatus: lessons from the reductive evolution of Mollicutes. PLoS Genet. 2014;10(5):e1004363. 
Gur E, Sauer RT. Evolution of the ssrA degradation tag in Mycoplasma: Specificity switch to a different protease. Proc Natl Acad Sci U S A. 2008; 105:16113-8.

Himeno H, Kurita D, Muto A. tmRNA-mediated trans-translation as the major ribosome rescue system in a bacterial cell. Front Genet. 2014;5:66-13.

Hong SJ, Tran QA, Keiler KC. Cell cycle-regulated degradation of tmRNA is controlled by RNase R and SmpB. Mol Microbiol. 2005;57: $565-75$.

Hudson CM, Lau BY, Williams KP. Ends of the line for tmRNA-SmpB. Front Microbiol. 2014:5:421-9.

IRPCM. 'Candidatus Phytoplasma', a taxon for the wall-less, non-helical prokaryotes that colonize plant phloem and insects. Int J Syst Evol Microbiol. 2004;54:1243-55.

Janssen BD, Hayes CS. The tmRNA ribosomerescue system. Adv Protein Chem Struct Biol. 2012;86:151-91.

Jollard C, Foissac X, Desqué D, Razan F, Garcion C, Beven L, et al. Flavescence dorée phytoplasma has multiple $\mathrm{ftsH}$ genes that are differentially expressed in plants and insects. Int $\mathrm{J} \mathrm{Mol}$ Sci. 2020;21.

Jones P, Binns D, Chang HY, Fraser M, Li W, McAnulla C, et al. InterProScan 5: Genomescale protein function classification. Bioinformatics. 2014;30:1236-40.

Karzai AW, Roche ED, Sauer RT. The SsrA-SmpB system for protein tagging, directed degradation and ribosome rescue. Nat Struct Biol. 2000; 7:449-55

Karzai AW, Susskind MM, Sauer RT. SmpB, a unique RNA-binding protein essential for the peptide-tagging activity of SsrA (tmRNA). EMBO J. 1999;18:3793-9.

Keiler KC. Biology of trans-translation. Annu Rev Microbiol. 2008;62:133-51.

Keiler KC, Waller PR, Sauer RT. Role of a peptide tagging system in degradation of proteins synthesized from damaged messenger RNA. Science. 1996;271:990-3.

Komine Y, Kitabatake M, Yokogawa T, Nishikawa $\mathrm{K}$, Inokuchi $\mathrm{H}$. A tRNA-like structure is present in 10Sa RNA, a small stable RNA from Escherichia coli. Proc Natl Acad Sci U S A. 1994;91:9223-7.

Kube M, Mitrovic J, Duduk B, Rabus R, Seemüller E. Current view on phytoplasma genomes and encoded metabolism. ScientificWorldJournal. 2012;2012:185942.

Kube M, Schneider B, Kuhl H, Dandekar T, Heitmann K, Migdoll AM, et al. The linear chromosome of the plant-pathogenic mycoplasma 'Candidatus Phytoplasma mali'. BMC Genomics. 2008;9:1-14.

Kube M, Siewert C, Migdoll AM, Duduk B, Holz $\mathrm{S}$, Rabus R, et al. Analysis of the complete genomes of Acholeplasma brassicae, A. palmae and A. laidlawii and their comparison to the obligate parasites from 'Candidatus Phytoplasma'. J Mol Microbiol Biotechnol. 2014;24: $19-36$.
Kumar S, Stecher G, Li M, Knyaz C, Tamura K. MEGA X: Molecular evolutionary genetics analysis across computing platforms. Mol Biol Evol. 2018;35:1547-9.

Kumari S, Nagendran K, Rai AB, Singh B, Govind Pratap Rao, Bertaccini A. Global status of phytoplasma diseases in vegetable crops. Front Microbiol. 2019;10:1-15.

Lazarev VN, Levitskii SA, Basovskii YI, Chukin MM, Akopian TA, Vereshchagin VV, et al. Complete genome and proteome of Acholeplasma laidlawii. J Bacteriol. 2011;193:494353.

Lee I-M, Gundersen-Rindal DE, Davis RE, Bartoszyk IM. Revised classification scheme of phytoplasmas based on RFLP analyses of $16 \mathrm{~S}$ rRNA and ribosomal protein gene sequences. Int J Syst Bacteriol. 1998;48(4):1153-69.

Li Z, Pandit S, Deutscher MP. 3' exoribonucleolytic trimming is a common feature of the maturation of small, stable RNAs in Escherichia coli. Proc Natl Acad Sci U S A. 1998;95: 2856-61.

Madigan MT, Bender KS, Buckley DH, Sattley MW, Stahl DA. Brock Mikrobiologie, ed 15 Pearson Deutschland GmbH; 2020.

Maejima K, Oshima K, Namba S. Exploring the phytoplasmas, plant pathogenic bacteria. J Gen Plant Pathol. 2014;80(3):210-21.

Manolukas JT, Barile MF, Chandler DK, Pollack JD. Presence of anaplerotic reactions and transamination, and the absence of the tricarboxylic acid cycle in Mollicutes. J Gen Microbiol. 1988;134:791-800.

Mao C, Bhardwaj K, Sharkady SM, Fish RI, Driscoll T, Wower J, et al. Variations on the tmRNA gene. RNA Biol. 2009;6.

Merhej V, Royer-Carenzi M, Pontarotti P, Raoult D. Massive comparative genomic analysis reveals convergent evolution of specialized bacteria. Biol Direct. 2009;4:13-25.

Miles RJ. Catabolism in mollicutes. J Gen Microbiol. 1992;138:1773-83.

Mitrović J, Kakizawa S, Duduk B, Oshima K, Namba S, Bertaccini A. The groEL gene as an additional marker for finer differentiation of 'Candidatus Phytoplasma asteris'-related strains. Ann Appl Biol. 2011;159:41-8.

Mushegian AR, Koonin EV. A minimal gene set for cellular life derived by comparison of complete bacterial genomes. Proc Natl Acad Sci U S A. 1996;93:10268-73.

Nakabachi A, Yamashita A, Toh $\mathrm{H}$, Ishikawa $\mathrm{H}$, Dunbar HE, Moran NA, et al. The 160-kilobase genome of the bacterial endosymbiont Carsonella. Science. 2006;314:267.

Nei M, Kumar S. Molecular Evolution and Phylogenetics. New York: Oxford University Press; 2000.

Notredame C, Higgins DG, Heringa J. T-coffee: A novel method for fast and accurate multiple sequence alignment. J Mol Biol. 2000;302: 205-17.
Oshima K, Kakizawa S, Nishigawa H, Jung HY, Wei W, Suzuki S, et al. Reductive evolution suggested from the complete genome sequence of a plant-pathogenic phytoplasma. Nat Genet. 2004;36:27-9.

Petrov AI, Kay SJE, Kalvari I, Howe KL, Gray KA, Bruford EA, et al. RNAcentral: A comprehensive database of non-coding RNA sequences. Nucleic Acids Res. 2017;45:D128-D134.

Ray BK, Apirion D. Characterization of 10S RNA: A new stable RNA molecule from Escherichia coli. Mol Gen Genet. 1979;174:25-32.

Razin S. The Mycoplasmas. Microbiol Rev. 1978; 42(2):414-70.

Richards J, Mehta P, Karzai AW. RNase R degrades non-stop mRNAs selectively in an SmpB-tmRNA-dependent manner. Mol Microbiol. 2006;62:1700-12.

Schneider B, Gibb KS, Seemüller E. Sequence and RFLP analysis of the elongation factor $\mathrm{Tu}$ gene used in differentiation and classification of phytoplasmas. Microbiology (Reading). 1997;143(Pt 10):3381-9.

Schönhuber W, Le Bourhis G, Tremblay J, Amann R, Kulakauskas S. Utilization of tmRNA sequences for bacterial identification. BMC Microbiol. 2001;1:20.

Seemüller E, Schneider B, Maurer R, Ahrens U, Daire X, Kison H, et al. Phylogenetic classification of phytopathogenic mollicutes by sequence analysis of $16 \mathrm{~S}$ ribosomal DNA. Int J Syst Bacteriol. 1994;44:440-6.

Seemüller E, Sule S, Kube M, Jelkmann W, Schneider B. The AAA+ ATPases and HflB/ FtsH proteases of 'Candidatus Phytoplasma mali': Phylogenetic diversity, membrane topology, and relationship to strain virulence. Mol Plant-Microbe Interact. 2013;26:367-76.

Shimizu Y, Ueda T. The role of SmpB protein in trans-translation. FEBS Lett. 2002;514:74-7.

Someya T, Nameki N, Hosoi H, Suzuki S, Hatanaka $\mathrm{H}$, Fujii M, et al. Solution structure of a tmRNA-binding protein, SmpB, from Thermus thermophilus. FEBS Lett. 2003;535:94100

Tamura K, Nei M. Estimation of the number of nucleotide substitutions in the control region of mitochondrial DNA in humans and chimpanzees. Mol Biol Evol. 1993;10:512-26.

Toruño TY, Seruga Musić M, Simi S, Nicolaisen M, Hogenhout SA. Phytoplasma PMU1 exists as linear chromosomal and circular extrachromosomal elements and has enhanced expression in insect vectors compared with plant hosts. Mol Microbiol. 2010;77:1406-15.

Tran-Nguyen LTT, Kube M, Schneider B, Reinhardt R, Gibb KS. Comparative genome analysis of "Candidatus Phytoplasma australiense" (subgroup tuf-Australia I; rp-A) and "Ca. phytoplasma asteris" strains OY-M and AY-WB. J Bacteriol. 2008;190:3979-91.

Tu GF, Reid GE, Zhang JG, Moritz RL, Simpson RJ. C-terminal extension of truncated recombinant proteins in Escherichia coli with a 10Sa RNA decapeptide. J Biol Chem. 1995;270: 9322-6. 
Ushida C, Himeno H, Watanabe T, Muto A. tRNA-like structures in 10Sa RNAs of Mycoplasma capricolum and Bacillus subtilis. $\mathrm{Nu}-$ cleic Acids Res. 1994;22:3392-6.

Wang J, Song L, Jiao Q, Yang S, Gao R, Lu X, et al. Comparative genome analysis of jujube witches'-broom Phytoplasma, an obligate pathogen that causes jujube witches'-broom disease. BMC Genomics. 2018;19:1-12.
Wei W, Davis RE, Jomantiene R, Zhao Y. Ancient, recurrent phage attacks and recombination shaped dynamic sequence-variable mosaics at the root of phytoplasma genome evolution. Proc Natl Acad Sci U S A. 2008;105:11827-32.

Withey J, Friedman D. Analysis of the role of trans-translation in the requirement of tmRNA for $\lambda \operatorname{imm}(\mathrm{P} 22)$ growth in Escherichia coli. J Bacteriol. 1999;181:2148-57.
Woese CR, Maniloff J, Zablen LB. Phylogenetic analysis of the mycoplasmas. Proc Natl Acad Sci U S A. 1980;77:494-8.

Zwieb C, Wower I, Wower J. Comparative sequence analysis of tmRNA. Nucleic Acids Res. 1999;27:2063-71. 